\title{
Comment to: A modified Chevrel technique for ventral hernia repair: long-term results of a single centre cohort. Mommers EHH, Leenders, B.J.M., Leclercq, W.K.G. et al.
}

\author{
J. Li ${ }^{1} \cdot$ W. Zhang ${ }^{1}$
}

Received: 30 August 2017 / Accepted: 15 September 2017 / Published online: 30 September 2017

(C) Springer-Verlag France SAS 2017

\section{Dear Editors:}

We read with great interest the recent article by Mommers [1], published in hernia. The authors reported favorable ventral hernia repair results with the modified Chevrel technique. Although various techniques have been described in the repair of ventral/incisional hernias, including onlay techniques and various sublay techniques, the ideal location of mesh placement remains heavily debated [2]. This debate very much resembles that of Lichtenstein technique vs preperitoneal repair in inguinal hernias. And similarly, both onlay and sublay techniques will play a role in ventral hernia repair. And no surprise, again, the debate will go on, since no one is perfect. The major concerns on the onlay mesh repair are the wide creation of the lipocutaneous flaps and potential wound complication. Thus, the present modified Chevrel technique seems a reasonable alterative to the original Chevrel technique. Although promising results were obtained from the author's present modified Chevrel technique, some points are needed to pay attention. First, the recurrence risk after ventral hernia repair depends largely on the extent of mesh overlap, despite of the mesh location. The modified Chevrel technique has the inherit limitation in sufficient overlap, since the mesh border within the lateral border of the rectus fascia, especially in large hernia defect, and this is no problem in sublay technique, e.g., with the transversus abdominis muscle release (TAR) technique [3]. The second point is the "meticulous suturing", which the

This comment refers to the article available at doi:10.1007/ s10029-017-1602-2.

$\triangle \mathrm{J} . \mathrm{Li}$

Lijunshenghd@126.com

1 Department of General Surgery, Affiliated Zhongda Hospital, Southeast University, Nanjing 210009, China author stressed that it will take "approximated $2 \mathrm{~h}$ " to complete. I would like to emphasize again the tenet that, the suture fixation could never substitute sufficient overlay in prosthesisbased hernia repair. Thus, in this point, I would question the necessity of the time-consuming suturing step, is it a compensation for the insufficient overlap, or a lack of confidence for this modification? Again, it is the overlap that matters, in spite of the mesh location, in the ventral hernia repair.

\section{Compliance with ethical standards}

Funding None.

Conflict of interest The author declares no conflict of interest.

Ethical approval For this type of study formal consent is not required.

Human and animal rights This article does not contain any studies with human participants or animals performed by any of the authors.

Informed consent Informed consent was obtained from all individual participants included in the study.

\section{References}

1. Mommers EHH, Leenders BJM, Leclercq WKG, de Vries Reilingh TS, Charbon JA (2017) A modified Chevrel technique for ventral hernia repair: long-term results of a single centre cohort. Hernia 21(4):591-600. doi:10.1007/s10029-017-1602-2 (Epub 2017 Apr 13)

2. Deerenberg EB, Timmermans L, Hogerzeil DP, Slieker JC, Eilers PH, Jeekel J, Lange JF (2015) A systematic review of the surgical treatment of large incisional hernia. Hernia 19:89-101

3. Novitsky YW, Elliott HL, Orenstein SB, Rosen MJ (2012) Transversus abdominis muscle release: a novel approach to posterior component separation during complex abdominal wall reconstruction. Am J Surg 2012(204):709-716 